\title{
A política de emprego no Brasil: 0 caminho da flexinsegurança*
}

\section{Employment policy in Brazil: the pathy of flexinsecurity}

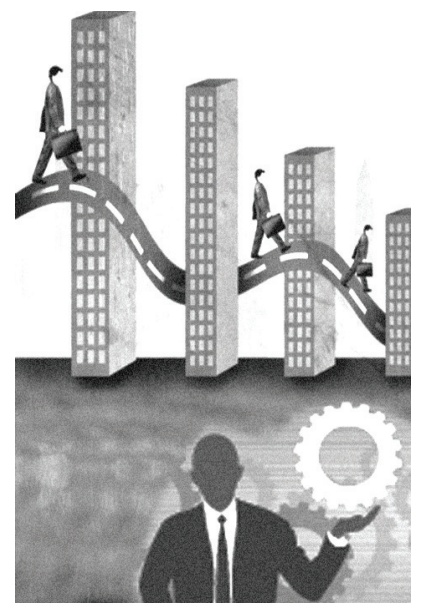

Ednéia Alves de Oliveira**

Resumo: Este artigo discute a política de emprego implementada no Brasil nos últimos vinte anos como resposta ao aumento do desemprego provocado pela crise estrutural e pela reestruturação produtiva, fruto do atual estágio de acumulação capitalista. No entanto, tais políticas têm apenas reforçado a precarização das condições de vida e de trabalho da classe trabalhadora ao flexibilizar direitos e contratos trabalhistas e criar programas de geração de renda que primam pelo assistencialismo ao promover renda aos comprovadamente pobres, distanciando-se da perspectiva de (re) inserção no mercado de trabalho.

Palavras-chave: Desemprego. Políticas de emprego. Assistencialismo.

\begin{abstract}
This article discusses the employment policy implemented in Brazil in the last 20 years as a response to rising unemployment caused by structural crisis and the restructuring of production, due to the current stage of capitalist accumulation. However, such policies have only reinforced the precarious conditions of life and work of the working class rights and flexible labor contracts and create income-generating programs that strive to promote the welfarism income to the poor proved to distancing themselves from the perspective of (re) integration into the labor market.
\end{abstract}

Keywords: Unemployment. Employment policies. Welfarism.

* Este artigo é referente a parte do capítulo 3 da pesquisa de doutorado sanduíche defendida em fevereiro de 2010 intitulada "A política pública de emprego: entre a precarização desprotegida e a precarização desprotegida. Um estudo comparativo entre Brasil e Itália”, pelo programa de pós-graduação em Serviço Social da Universidade do Estado do Rio de Janeiro e da Universidade de Bolonha.

** Professora Adjunto da Universidade Federal de Ouro Preto/MG, Brasil, lotada no Departamento de Comunicação Social e Serviço Social (DECSO).E-mail: oliveiraedneia@ig.com.br. 


\section{Introdução}

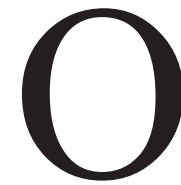

desemprego se constitui um dos maiores problemas sociais da humanidade. A crise iniciada nos países centrais a partir do final dos anos 1960 evidenciou o esgotamento do padrão de acumulação fordista keynesiano, alterando a relação entre Estado e sociedade. Essa crise foi atribuída, entre outros fatores, à necessidade de retomada da competividade industrial e das taxas de lucro. Para garantir esse novo estágio foi desenvolvida uma nova engenharia produtiva que, associada às inovações tecnológicas, provocaram a expulsão de milhares de trabahadores do mercado formal de trabalho em todo o mundo. Estima-se, segundo relatório da Organização Internacinal do Trabalho (OIT), que o número de desempregados no mundo atingiu, em 2009, a casa dos 210 milhões de trabalhadores. Esses dados podem ser ainda maiores se for contabilizado o desemprego oculto e o trabalho informal. Os maiores afetados, segundo a agência, são os jovens e as mulheres dos países periféricos. Para reverter a crise do desemprego, as agências multilateriais têm preconizado a implementação de programas e políticas de geração de emprego e renda para esses países, ao mesmo tempo que defendem a criação de formas mais flexíveis de contratos de trabalho e a desregulamentação das leis trabalhistas, além, é claro, do empreendedorismo e da informalidade, acreditando ser o caminho mais eficaz para estimular os índices de empregabilidade.

\section{1930-90: As primeiras medidas de regulamentação do trabalho}

No caso do Brasil, a política de emprego está intrinsecamente relacionada à frágil concepção de Welfare State e à posição ocupada pelo país na divisão internacional do trabalho, reforçando um crescimento subordinado e dependente do capital estrangeiro, com uma política inflacionária e de alto endividamento externo e interno. O legado histórico do trabalho negro e escravo no país, associado à perseguição política de lideranças de esquerda pelos governos ditatoriais, impediu o fortalecimento de uma organização sindical autônoma e representativa dos interesses da classe trabalhadora, resultando no favorecimento da exploração do trabalho e nos baixos salários pagos ao trabalhador. Além da influência fascista da legislação trabalhista, o Brasil conviveu com longos períodos ditatoriais, subordinando a política social ao desempenho econômico. O consenso era obtido, em grande parte, mediante a repressão e contenção das manifestações populares ou por meio da 
concessão de políticas sociais corporativas somente para determinados ramos da produção.

Resulta daí a ausência histórica de uma política social de proteção ao trabalhador, principalmente dos desempregados, e apenas um conjunto de leis que regulamentava o mercado de trabalho, primando pela necessidade de harmonizar os conflitos entre capital e trabalho. Um exemplo paradigmático foi o avanço das greves e a resposta do Estado em 1919, com a lei sobre acidentes de trabalho, responsabilizando empregadores e os vários níveis de governo pela indenização. Outra medida importante na tentativa de regulamentar as relações de trabalho nesse período foi a criação do aviso prévio de oito dias para as demissões, a proibição do pagamento de salários atrasados e de compensação de horas extras por outras formas que não a salarial, estabilidade no emprego para portuários e ferroviários e a proibição do trabalho para menores de catorze anos de idade.

Posteriormente, foi criada a Caixa de Aposentadoria e Pensão dos Ferroviários (CAPs). A criação da CAPs pode ser considerada uma das primeiras medidas de proteção social aos trabalhadores, apesar de seu caráter corporativo e limitado. Somente a partir da década de 1930 é que o Estado brasileiro vai exercer uma intervenção mais sistemática na proteção do trabalhador. De acordo com Fausto (1995), essa intervenção do Estado no sistema de proteção social foi resultado da própria necessidade de obter maior consenso entre os trabalhadores, de forma a promover a industrialização do país. Data desse período a criação do Ministério do Trabalho, Comércio e Indústria e o estabelecimento da jornada de oito horas diárias, além da proibição do trabalho infantil noturno. A política ditatorial de Vargas apostava na conciliação de classes para promover o processo de acumulação capitalista no país, e para garantir esse estágio foi promulgada, em 1943, a Consolidação das Leis Trabalhistas (CLT), inspirada na Carta del Lavoro, promulgada por Mussolini na Itália com a ênfase na cooperação entre capital e trabalho e no fim do sindicalismo autônomo. Essa concepção burocrática e subordinada será mantida por todo o período do governo Vargas, e somente a partir de 1945 é que haverá um recrudescimento das lutas operárias. Esse período de silêncio foi importante para o capital consolidar o seu processo de acumulação e garantir as bases de um mercado de trabalho, já naquele período, bastante flexível e móvel (Oliveira, 2010).

Diante do exposto, pode-se notar que as principais medidas de proteção ao trabalhador no Brasil foram no sentido de controlar a força de trabalho com a inserção de marcos regulatórios corporativos e restritos a pequenos grupos. A inexistência de uma política passiva de proteção aos trabalhadores ampliou a pobreza e criou um mercado de subsistência fora do núcleo formal da economia e dos direitos 
sociais, formando um excedente de força de trabalho e ampliando o quadro de exclusão social no país. Paralelo à ausência de uma política de emprego passiva de proteção ao trabalhador desempregado, pode-se dizer que foram implementadas, nesse período, as primeiras medidas de uma política ativa de emprego. A criação de escolas de formação e qualificação da força de trabalho jovem do país, em 1940, por meio do Serviço Nacional de Aprendizagem Industrial (SENAI), do Serviço Nacional de Aprendizagem Comercial (Senac) e das Escolas Técnicas Federais, permitiu a formação de um mercado de trabalho qualificado e excedente para atender o setor urbano industrial em expansão e financiadas com recursos públicos para qualificação de adolescentes e jovens para o mercado de trabalho, oferecendo cursos de baixo custo nas áreas de maior demanda.

Nos anos sucessivos, a política de emprego continuou subordinada ao crescimento econômico, com investimentos em infraestrutura e com incentivo à entrada de empresas estrangeiras. Os investimentos em obras de infraestrutura favoreceram a ampliação do mercado de trabalho, principalmente no setor de construção civil. A entrada de empresas estrangeiras na produção de bens duráveis também permitiu a ampliação de um mercado de trabalho urbano, principalmente nas grandes metrópoles. Nessas cidades formaram-se nichos operários, atraídos pela promessa de trabalho, fomentando o êxodo rural, revelando a precariedade das condições de vida da população. A falta de saneamento básico, de uma política habitacional, a permanência de um sistema de saúde excludente e da educação apenas para o mercado e para poucos eram evidências da opção pelo crescimento econômico em detrimento de uma política social voltada para atender a classe trabalhadora em expansão. $\mathrm{Ou}$ seja, mais uma vez apostava-se na política macroeconômica de crescimento para promoção de emprego e da renda, conjugando as políticas de acumulação com as políticas de desigualdade.

No início de 1960 as reformas sociais entram na pauta do governo. O clima de luta e contestação popular associado às propostas de reformas de base não agradou a elite nacional, principalmente aquela ligada aos interesses do capital estrangeiro. Para eles, a perspectiva de uma reforma mais ampla colidia com o processo de acumulação capitalista em curso no país. Dessa forma, criaram mecanismos para impedir a consolidação do projeto reformista e deter o avanço das lutas populares. Mas se durante o período de 1945 a 1964 houve poucas iniciativas na implementação de uma política social e trabalhista, os anos de 1964 em diante serão marcados por algumas mudanças que incidirão na política de emprego brasileira. A necessidade do governo militar em promover a maior produtividade do trabalho em face da expansão industrial e tecnológica redundou em medidas coercitivas. A 
primeira delas foi a proibição do direito de greve, com a Lei Antigreve em 1964 sendo seguida da política de contenção salarial, como exemplifica a Lei n. 4.725, de 1965. Paralelamente às medidas coercitivas, o governo buscou garantir sua legitimidade por meio de medidas que compensassem a ausência de liberdade e de expressão, criando algumas políticas que beneficiaram, de certo modo, os trabalhadores, ampliando alguns direitos e estendendo os benefícios para categorias profissionais historicamente excluídas da política trabalhista. A primeira delas foi a unificação e a centralização da Previdência Social no Instituto Nacional de Previdência Social (INPS), em 1966, e posteriormente a inclusão dos acidentes de trabalho também sob gestão do INPS (Behring e Boschetti, 2008). Desta forma, unificou todos os institutos, com exceção do Ipase, e uniformizou os serviços e benefícios. Ainda nesse período destaca-se a criação do Fundo de Garantia por Tempo de Serviço (FGTS), que na prática substitui o capítulo da estabilidade, assegurada na CLT, pela poupança compulsória.

Em 1970, o governo criou o Programa de Integração Social (PIS), beneficiando os trabalhadores urbanos e da iniciativa privada. Para compensar, criou ainda o Programa de Formação do Patrimônio do Servidor (Pasep) para os funcionários públicos. Outra medida criada pelos militares foi o Prorural, em 1971, programa a ser executado pelo Funrural. Essa foi a primeira legislação para a criação de um sistema previdenciário que beneficiasse os trabalhadores rurais, benefício ampliado às empregadas domésticas e, em 1973, aos trabalhadores autônomos. Essa inclusão tardia dos trabalhadores rurais, domésticos e autônomos evidencia a política trabalhista corporativa e excludente do Brasil e denota a ausência de um sistema de garantias sociais para o conjunto da classe trabalhadora e dos trabalhadores fora do mercado de trabalho.

A criação do Ministério da Previdência e Assistência Social (MPAS) em 1974 e a incorporação de algumas entidades assistenciais foi uma tentativa de promover políticas de assistência aos trabalhadores excluídos do mercado formal de trabalho. Na prática, contudo, prevaleceu a legislação favorável àqueles já inseridos no mercado de trabalho, como exemplifica a Lei n. 6.136, incluindo o salário-maternidade nos benefícios a serem pagos aos trabalhadores. Somente a Lei n. 6.179 pode ser considerada uma política mais abrangente, pois definia um auxílio previdenciário, pensões e assistência médica aos idosos pobres com mais de setenta anos e aos inválidos, desde que houvessem contribuído por pelo menos doze meses para o INPS, e a extensão do seguro acidente de trabalho para a área rural com a Lei n. 6.195. Portanto, é somente a partir de 1970 que o governo brasileiro começa a implementar algumas políticas passivas de emprego, mas que em virtude 
dos valores pagos e dos critérios de elegibilidade não conseguiam garantir minimamente a sobrevivência do trabalhador fora do mercado de trabalho.

No que se refere à política ativa, foi instituído em 1974, por meio da Lei n. 6.019, o regime de trabalho temporário para atender às necessidades do empresariado na contratação de força de trabalho para substituição de pessoal ou para contratação de trabalho extra (Marconsin, 2009). Em 1975 foi criado o Sistema Público de Emprego (SPE), marcado pela criação do Sistema Nacional de Emprego (Sine), por meio da Portaria n. 76.403, sob a supervisão e coordenação do Ministério do Trabalho. As linhas de ação eram voltadas para informar sobre o mercado de trabalho, implantar serviços e agências de emprego em todo o país, estabelecer o perfil do trabalhador brasileiro, informar às empresas sobre a força de trabalho disponível e a formação e qualificação da força de trabalho. Contudo, tais ações se revelaram inócuas, não abarcando os objetivos propostos.

Somente na década de 1980 é que a política social vai ser alvo de mudanças mais profundas. $\mathrm{O}$ esgotamento do regime militar e a crise econômica que se instaurou no país revelaram a precariedade das condições de vida da população brasileira e reacendeu o debate por melhores serviços de infraestrutura e de inclusão nos programas sociais, possibilitando a emergência de movimentos sociais urbanos que clamavam por direitos sociais e pela redemocratização no país. Nesse período destaca-se a criação, em 1986, do seguro-desemprego e a redução da jornada de trabalho de 48 para 44 horas. Essas foram as duas políticas ativas de emprego mais importantes dos anos de 1980 para a classe trabalhadora, segundo Pochmann (2008). A primeira porque passa a atender os desempregados do mercado formal, e a segunda por permitir maior ampliação do número de vagas no mercado de trabalho.

Outras medidas de regulamentação das relações trabalhistas foram criadas na década de 1980: a jornada de trabalho de seis horas para os regimes de turno, ampliação da licença-maternidade para 120 dias, regulamentação da licença-paternidade em cinco dias, adicional de férias de $1 / 3$ e o estabelecimento da hora extra em $50 \%$. Nota-se, porém, que não havia uma preocupação sistemática em criar políticas passivas para atender aos desempregados, mas apenas marcos regulatórios para o trabalhador formal. Ou seja, as medidas não abarcavam a classe trabalhadora como um todo, mas se voltavam mais uma vez para os trabalhadores inseridos no mercado formal de trabalho. Diante do aumento do desemprego, acenavam com benefícios limitados que atendiam parcialmente aos trabalhadores demitidos. Quanto à regulamentação da jornada de trabalho em 44 horas, tal medida se revelou insignificante, tendo em vista que o mercado de trabalho sempre foi muito despro- 
tegido, revelando o acúmulo de horas trabalhadas sem contrapartida por parte dos empregadores

\section{1990: a consolidação do projeto neoliberal e da lógica da flexinsegurança}

Os anos de 1990 foram um divisor de águas na política social brasileira, principalmente aquelas referentes ao mundo do trabalho. Como já analisado, o país sempre conjugou políticas macroeconômicas com políticas assistencialistas, limitando-se apenas a introduzir marcos regulatórios para algumas categorias profissionais, sem, contudo se debruçar na construção de uma política de emprego passiva ou ativa que contemplasse a subsistência ou a (re)inserção dos trabalhadores expulsos do mercado de trabalho. Acresce-se a esse fator as medidas impostas pelas agências multilaterais para reduzir os gastos públicos. Portanto, os anos 1990 serão marcados por tendências paradoxais. Primeiro porque pela primeira vez o país promulga a Carta Constitucional em 1988, com princípios universalistas, estabelecendo uma ruptura com a concepção minimalista de cidadania imposta até então pelos governos populistas e antidemocráticos. De inspiração explicitamente liberal, a Constituição de 1988 estabelece o trabalho como um direito inalienável e que deve ser garantido pelo Estado, assim como as demais políticas sociais. Mas se tal direito aparece como um dos pilares de sustentação da ordem social, ele vem assegurado no momento de transformação do mercado de trabalho.

Ou seja, as mudanças no padrão de organização do trabalho em consonância com as políticas macroeconômicas de estabilização econômica impostas pelo FMI e demais organismos multilaterais delimitaram a intervenção do Estado, provocando um acirramento da questão social em suas variadas expressões. É sob esta perspectiva que as políticas de emprego passam a ser implementadas no governo FHC. Ou seja, políticas que possam combater a crise do emprego e, consequentemente, a fome e a miséria, mas com recursos reduzidos e com ênfase na individualização do problema, reforçando a histórica intervenção residual do Estado brasileiro na questão social.

Um exemplo paradigmático foi criação do seguro-desemprego, considerado um dos maiores programas de atenção ao trabalhador brasileiro. Por meio da Lei n. 7.998, de 1990, foi definida também a concessão do abono salarial e a criação do Fundo de Amparo ao Trabalhador (FAT), financiado com os recursos do PIS/ Pasep e com a criação do Conselho Deliberativo do FAT, o Codefat. A criação do FAT foi um marco importante, pois definiu os recursos para a execução do seguro- 
-desemprego, permitindo finalmente sua efetivação. Em 1994, o seguro-desemprego sofreu modificações e teve sua base ampliada, aumentando também o tempo de indenização. Nesse período, o desemprego apresentava números elevados, chegando a atingir, de acordo com o IBGE, em torno de $17 \%$ da PEA. A renda média do trabalhador apresentou queda pelo sexto ano consecutivo, atingindo em 2003 uma redução de $12,9 \%$.

A implementação de contratos atípicos também foi uma justificativa para reduzir os custos de contratação e gerar mais empregos. De acordo com as justificativas do capital, os custos do trabalho impediam as empresas de contratar mais empregados, portanto competia ao Estado promover "reformas" flexibilizando a legislação para estimular as taxas de ocupação. Por outro lado, havia uma preocupação em romper com a rigidez do período fordista (embora no Brasil tal rigidez não tenha acontecido) e permitir maior liberdade aos empregadores na contratação e demissão de pessoal. O discurso da retomada da competitividade foi uma estratégia importante para garantir, política e ideologicamente, a extração dos superlucros, possível apenas por meio da queda dos custos dos fatores de produção. Nesse sentido, os custos do trabalho passam a ser atacados, mesmo nos países onde jamais foram significativos, como foi o caso do Brasil. Ou seja, mais uma vez, a saída da crise aparece nos discursos políticos como uma questão de ordem natural e que depende de medidas em conjunto para sua superação. Portanto, a flexibilização e a desregulamentação da legislação trabalhista, assim como o enfraquecimento das organizações representativas dos trabalhadores, foram estratégias importantes na consolidação da contrarreforma trabalhista. Ao Estado competia a tarefa de criar os mecanismos para implementar as mudanças, mas abstendo-se da responsabilidade de criar políticas de proteção social aos trabalhadores e, fundamentalmente, eliminando as barreiras para tornar o trabalho menos oneroso para os empregadores com a redução dos encargos sociais.

É neste sentido que o Estado brasileiro estabelece a criação dos contratos por tempo determinado, o contrato parcial, temporário, as cooperativas de trabalho, o trabalho-estágio, a suspensão do contrato e posteriormente a economia solidária no governo Lula. Essas mudanças nas leis foram apresentadas pelo governo como medidas de políticas de emprego que, associadas aos programas de geração de renda, minimizariam os efeitos dessa flexibilização. Paralelo aos contratos atípicos, o governo também investiu em programas de geração de emprego e renda, como ilustra a criação do Plano Nacional de Formação Profissional (Planfor), extinto no início do governo Lula, que em seu lugar criou o Programa Jovem e o Primeiro Emprego, ambos voltados para jovens da periferia com baixo poder aquisitivo, o que na prática não alterou a estrutura e os objetivos do programa anterior. 
Na mesma linha de atuação foi criado em 1995 o Programa de Geração de Emprego e Renda (Proger), "com o objetivo de atender e beneficiar pequenos e microempreendedores, microempresas, microempreendimentos formais ou informais, cooperativas e formas associativas de produção, assim como a promoção da agricultura familiar" (Cardoso, 2002, p. 21). Os recursos provenientes do FAT se inscreviam na base dos programas de combate à pobreza tanto no campo quanto na cidade, por meio do incremento da lógica empreendedora. No campo estavam vinculados à proposta do Programa Nacional de Agricultura Familiar (Pronaf), criado em 1995. Assim como o Planfor, este tinha uma perspectiva democrática, ao permitir a participação e a representação das partes sociais. O governo criou ainda, em 1996, o Programa de Expansão do Emprego e Melhoria da Qualidade de Vida do Trabalhador (Proemprego). Este programa foi financiado também com recursos do FAT e do Banco Nacional de Desenvolvimento Social (BNDES). Para melhorar sua eficácia, o programa foi sofrendo alterações nos anos seguintes e, em 2002, por meio da Resolução n. 289, o Proemprego III estabelecia, como objetivo primordial, "preservar e expandir oportunidades de trabalho, incrementar a renda do trabalhador, proporcionar a melhoria da qualidade de vida da população, em especial das camadas de baixa renda, e proporcionar a redução dos custos de produção no contexto internacional". Como se pode perceber, essas foram as principais medidas de uma política ativa de emprego no Brasil na gestão de FHC. Ou seja, a criação de contratos atípicos e de programas voltados para atender a população de baixa renda e que envolviam atividades tanto na zona rural quanto nas cidades. Porém, de acordo com Pochmann (2008), tais iniciativas foram muito tímidas, pois enquanto o desemprego crescia em proporções elevadas, os gastos com as políticas ativas, no período de 1995 a 2000 não chegaram a 1\% do PIB. Ou seja, em 1995, para um total de 4,5 milhões de desempregados, o governo investiu apenas $0,62 \%$. Em 2000, quando o número de desempregados chegava a 11,5 milhões, os investimentos em políticas de emprego foram de apenas $0,89 \%$. Como se pode perceber, os programas destinados a gerar empregos não obtiveram os êxitos esperados, e durante toda a década de 1990 o número de desempregados continuou a crescer.

Com relação à política passiva, a implementação do seguro-desemprego foi uma conquista importante, mas, devido a sua cobertura restrita, ele não abarcava os trabalhadores informais e domésticos, limitando-se apenas a prover a renda aos trabalhadores formais expulsos do mercado de trabalho e por um curto período de tempo. Portanto, os anos 1990 no Brasil foram marcados pelo aumento da flexibilização e da desregulamentação das relações trabalhistas e também pela expansão do quadro de pobreza da população, resultado do desemprego, do avanço do trabalho informal e da queda do poder aquisitivo da classe trabalhadora. 
Tendo em vista os escassos investimentos e os resultados ineficazes das políticas de emprego, o governo se volta para a adoção de programas de transferência de renda. Ainda no início de 1990, o discurso da implementação de um programa de transferência de renda de alcance nacional começou a ser discutido no governo. O marco inicial foi a aprovação da Lei n. 80/1991, do senador Suplicy. Nos anos subsequentes, os programas de transferência de renda passaram a ganhar espaço na arena política, e sua proposta passou a ser vinculada à questão da escolaridade. $\mathrm{Ou}$ seja, para garantir o acesso aos programas, as famílias deveriam retirar seus filhos da rua e inseri-los e mantê-los na escola. É nesse contexto que o programa Bolsa-Escola ganha espaço na cena política, transformando-se posteriormente no carro-chefe da política de assistência social do governo Lula, sob a denominação de Bolsa-Família, programa que unificou o Bolsa-Escola com outros programas menores de transferência de renda.

Com relação à política de emprego, o governo intitulado democrático-popular conjuga retirada de direitos com vistas a ampliar o número de vagas no mercado de trabalho com políticas assistencialistas para os mais pobres. Tal fato pode ser comprovado pelas alterações previdenciárias, o cerceamento do direito de greve, ao definir a competência do Ministério Público do Trabalho na defnição dos casos de legitimidade de uma ação grevista em setores considerados essenciais à prestação de serviços. Inseriu ainda o termo "de comum acordo", flexibilizando a ação da Justiça do Trabalho ao estabelecer que os dissídios só poderão ser decididos na Justiça do Trabalho quando estiverem acordados entre trabalhadores e empregadores, significando perda para os trabalhadores e enfraquecendo o poder dos sindicatos. Outra medida de precarização das relações de trabalho é a redução do tempo de repouso e alimentação para os trabalhadores, aumentando a produtividade do trabalho. Ainda nessa mesma perspectiva foi criada a lei que estabelece o contrato temporário no setor rural, sem a assinatura da carteira, sendo regido apenas por um contrato. E por fim temos a extensão dos contratos temporários para as empresas terceirizadas, reduzindo ou excluindo o trabalhador de qualquer direito trabalhista, com salário inferior, embora com jornada diária de trabalho de oito horas.

Portanto, as medidas adotadas para combater o desemprego no governo Lula foram no sentido de reformular aquelas já existentes ou ainda criar algumas iniciativas inovadoras para atingir o público-alvo definido como prioridade pelas agências multilaterais. Desta forma, destacam-se: I) o Programa de Aprendizagem Profissional regulamentado em 2005. Embora fosse já previsto pela CLT em 1943, ele sofre reformulações que alteram o decreto-lei anterior e estabelece que os contratos atuais terão registro em CTPS, férias anuais em consonância com as férias escolares, $13^{\circ}$ salário, FGTS (alíquota reduzida para $2 \%$ ) e jornada de seis horas diárias, 
além da frequência na escola e inscrição em programas de aprendizagem desenvolvidos sob a orientação de entidade qualificada em formação técnico-profissional. Em 2005 ampliou-se a idade do jovem aprendiz para 24 anos, por meio do Decreto n. 5.598. Em 2007 foi criado o Cadastro Nacional de Aprendizagem para viabilizar o registro de entidades de formação técnico-profissionais responsáveis pela qualificação de jovens. Essas entidades são representadas pelo Sistema S tradicional e o Serviço Nacional de Aprendizagem do Cooperativismo (Sescoop), além, é claro, das escolas técnicas de educação. A carga horária deve ser dividida entre o trabalho na empresa e curso de aprendizagem. Compete ao Ministério do Trabalho e do Emprego (MTE) impedir que as vagas dos trabalhadores adultos sejam substituídas pelos aprendizes.

Em 2003 foi criado o Programa Nacional de Estímulo ao Primeiro Emprego (PNPE). Esse programa objetivava gerar empregos para os jovens entre 16 e 24 anos com ênfase no empreendedorismo, responsabilidade social e aprendizagem (MTE, 2008). Aqueles que não são inseridos imediatamente no mercado formal de trabalho ou possuem espírito empreendedor são estimulados a criar cooperativas de trabalho. O público-alvo desse programa são jovens sem qualificação profissional, com renda per capita de meio salário mínimo e em situação de risco social. Para estimular a maior contratação de jovens, o governo alterou o programa em 2004, aumentando o valor dos incentivos pagos às empresas que aderiam ao PNPE. Criou também novas facilidades operacionais, como o Sigo, um sistema de informações que trabalha em parceria com os Consórcios Sociais da Juventude e com o Sine. A preocupação do governo é reduzir o emprego juvenil, pois, como afirma o documento, $45 \%$ dos desempregados no país é composto por jovens e mulheres. Incentivar as empresas significa desenvolver o espírito de responsabilidade social, em que a empresa abre mão da subvenção econômica de $\mathrm{R} \$ 250,00$ por jovem contratado e contrata diretamente, evitando burocracias. De acordo com os dados do MTE, cerca de 208 mil jovens estão em processo de qualificação e 47 mil já foram inseridos no mercado de trabalho. Este programa foi extinto em 2006, devido à sua ineficácia, pois apenas 3.936 jovens foram inseridos no mercado de trabalho, contrariando as expectativas, que eram de gerar 260 mil vagas por ano. Ainda em 2003 foi criado o Programa Economia Solidária em Desenvolvimento considerado um instrumento importante no combate à pobreza e na promoção da "inclusão social". "O trabalhador é organizado de forma coletiva, gerindo seu próprio trabalho e lutando pela emancipação". ${ }^{1}$ Para dar viabilidade ao programa foi criada a Secretaria Nacional de Economia Solidária (Senaes), incorporada ao MTE. Por

1. Disponível em: $<$ http//www.mte.economiasolidaria.org > . Acesso em: 15 ago. 2010. 
meio de iniciativas de Organizações não Governamentais (ONGs), tem suas ações voltadas para a construção de projetos produtivos coletivos e empreendimentos populares solidários, empresas recuperadas por trabalhadores e com propostas de autogestão, cooperativas de agricultura familiar, de prestação de serviços, entre outras. O programa de economia solidária busca criar uma articulação com todas as instâncias produtivas do governo federal, como secretarias de pesca e agricultura, do desenvolvimento territorial e de promoção da igualdade e da cidadania. Articula-se às políticas de assistência social, como o Bolsa-Família e o Fome Zero. Ou seja, é um programa integrado aos vários setores governamentais e se insere na política de geração de emprego e renda com vistas a promover um desenvolvimento mais justo e solidário.

Para Barbosa (2007), a proposta de economia solidária no governo Lula é a de regulação social do cooperatvismo. Um novo tipo de regulação por meio do autoemprego, em substituição ao anterior, baseado na inserção no mercado formal de trabalho. Aqui se fala porém de um "novo" cooperativismo, baseado na participação e nas ações democráticas. Para o governo Lula, é primordial investir nas pequenas unidades produtivas como forma de reverter as altas taxas de desemprego no país e possibiltar o aumento da renda e acesso aos bens públicos. O lema é cooperar e produzir, enfatizando o dinamismo econômico e a eficiência produtiva. Neste sentido, percebe-se que a economia solidária não se distingue dos outros programas de geração de emprego e renda quando aposta no empreendedorismo e no cooperativismo, reforçando a capacidade humana e a autonomia dos indivíduos. Ou seja, a economia solidária caminha na direção dos programas defendidos pelas agências multilaterais para os paises em desenvolvimento. Desregulamentar e flexibilizar, mas ao mesmo tempo promover políticas que apostem na capacidade individual dos sujeitos e no incremento do autoemprego, principalmente nas regiões mais pobres do campo e da cidade.

Não é por acaso que as recomendações da OIT com relação às políticas de emprego são no sentido de fomentar o empreendedorismo e o cooperativismo. Para a OIT, o empreendedorismo e o cooperativismo são soluções para reverter as mazelas provocadas pelos ajustes estruturais no mundo. Neste sentido a OIT, em parceria com a Aliança Cooperativista Internacional (ACI), desenvolve convênios de atividades e fomento à promoção do cooperativismo no mundo. Neste contexto cabe o desenvolvimento das potencialidades individuais para gerar oportunidades de emprego com a criação de pequenas empresas, principalmente nas áreas mais pobres. Ou seja, a recomendação é investir no trabalho informal, sem proteção e precário (Oliveira, 2010). 
Dentro dessa lógica foi criado, em 2005, o Programa Nacional de Microcrédito Produtivo Orientado (PNMPO). Esse programa visa incentivar a geração de trabalho e renda entre os microempreendedores populares, disponibilizar recursos para o microcrédito e oferecer apoio técnico às instituições de microcrédito produtivo. Para facilitar a expansão do empreendedorismo, o governo tem procurado criar mecanismos para reduzir os impostos de forma a desonerar as pequenas e médias empresas, como demonstra a criação do Super Simples Nacional, em 2006. Para Marconsin (2009), esse novo imposto foi uma estratégia para simplificar as relações de trabalho sob a justificativa de diminuir a taxação sobre as pequenas e médias empresas. Sob a defesa de reduzir os encargos fiscais que normalmente dificultam a sobrevivência dessas empresas no país, o governo Lula abriu um precedente para precarizar as condições de trabalho, pois as isentam de anotar sobre férias e fixação de quadro de horários de trabalho dos respectivos funcionários. Prevê ainda a dispensa dessas empresas de matricular os seus aprendizes em cursos dos Serviços Nacionais de Aprendizagem.

Outro exemplo dessa tendência de transferência de renda e de individualização do problema do desemprego é a criação do Programa Nacional de Inclusão de Jovens (ProJovem). Voltado para a população jovem, como o próprio nome indica, esse programa está integrado às modalidades do Juventude Cidadã e dos Consórcios Sociais da Juventude. Seu objetivo é reintegrar o jovem ao processo educacional, qualificando profissionalmente e proporcionando seu desenvolvimento humano. Também visa gerar renda aos jovens inseridos nos programas. Para beneficiar maior número de pessoas, o programa foi dividido em quatro frentes: o ProJovem Adolescente, para aqueles entre 15 a 17 anos, egressos do Programa de Erradicação do Trabalho Infantil (Peti), dos programas de combate ao abuso e exploração sexual, de medidas socioeducativas e de proteção e integrantes de famílias beneficiadas pelo Programa Bolsa Família. O ProJovem Trabalhador também contempla os jovens com auxílio de até seis prestações; o ProJovem Campo, com até 12 auxílios financeiros, e o ProJovem Urbano, com até 20 benefícios. Estes últimos são destinados a uma faixa etária de 18 a 29 anos, e a concesssão do benefício está condicionada aos critérios de renda familiar. Ou seja, os jovens devem pertencer a famílias que possuam renda per capita de até meio salário mínimo. Como o objetivo é elevar a escolaridade, qualificar profissionalmente e gerar ocupações alternativas para promover renda, o jovem deve ter um bom rendimento escolar e comportamental. Ainda dentro dos programas de inserção dos jovens, existe o incentivo à responsabilidade social por parte das empresas. Estas recebem um selo de "Parceiros da Juventude" por se dedicarem a qualificar, formar e inserir os adolescentes e jovens no mercado de trabalho. 
Diante do exposto, pode-se constatar que os dois últimos programas criados pelo governo Lula tem uma ênfase muito grande na difusão do empreendedorismo e da renda. São programas afinados com as diretrizes internacionais, configurando-se como medidas de geração de renda sem qualquer vinculação com a promoção do emprego. Isto pode ser comprovado pelos objetivos definidos pelos programas, qual seja: gerar renda e estimular o desenvolvimento de pequenas empresas. Como todos esses programas se inserem no programa maior, que é o combate à fome e a miséria, podemos afirmar que representam apenas medidas paliativas para os jovens pobres da periferia, jogando sobre seus ombros a responsabilidade de manutenção da família, exigindo em contrapartida o bom desemprenho escolar e comportamental. Um nítido viés de culpabilização e responsabilização dos mais pobres, em que o fracasso ou sucesso dependerá exclusivamente da sua capacidade de aproveitar as "oportunidades" oferecidas.

A ineficácia de tais programas está expressa na permanência das taxas de desemprego, que continuam inalteradas e atingem, principalmente, jovens, mulheres ou trabalhadores com baixa qualificação. Para estes o desemprego continua atingindo cerca de $40 \%$ da PEA, e os números apontam que não há uma tendência a alterações. Grande parte desse contingente, ou seja, jovens e trabalhadores de baixa qualificação, encontra-se excluídas das estatísticas do desemprego pela inserção nos programas de geração de renda, pelo desemprego por desalento e oculto e pela inserção no mercado informal. Estes não são contabilizados pelos organismos responsáveis pela divulgação das taxas de desemprego, o que tem levado o governo Lula a comemorar os "bons" números da empregabilidade no Brasil, que apenas mascaram a atual realidade, pois ignoram a informalidade, considerada nos dias atuais como atividade empreeendedora, reforçando o individualismo e as saídas alternativas para a crise do emprego, desonerando o Estado e permitindo ao capital seguir seu processo de acumulação capitalista.

\section{Conclusão}

As políticas de emprego implementadas nos últimos anos seguem a tendência das políticas sociais dentro da ordem do capital. São utilizadas como mecanismo de contenção dos conflitos e de manutenção da ordem, servindo como instrumento para minimizar os impactos das mudanças em curso. Não eliminam o caráter contraditório das relações sociais de produção capitalistas, mas acentuam o progresso da acumulação. Outra tendência das políticas de emprego é o fomento da coopera- 
ção solidária ou de ações empreendedoras que reforçam ainda mais o quadro de precariedade do trabalho. Esta lógica do empreendedorismo e do cooperativismo visa, sobretudo, estimular o trabalhador a ser independente e patrão de si mesmo, desonerando o Estado da responsabilidade de investimento em programas e políticas sociais, repassando tal responsabilidade para o indivíduo ou para a sociedade civil, revelando-se como uma flexinsegurança, pois retira ou flexibiliza direitos conquistados, além de não garantir a (re)inserção do trabalhador no mercado formal de trabalho. Se o objetivo fosse a geração de emprego, bastaria a redução da jornada de trabalho, a redução da idade de aposentadoria, a permanência dos jovens na escola, a reorganização do trabalho, o que, de acordo com Marx (1988, p. 739), tornaria a população trabalhadora existente insuficiente para prosseguir com a produção na sua escala atual, representando o fim da exploração do trabalho e da extração da taxa de mais-valia, permitindo o resgate da concepção do trabalho como elemento de libertação e emancipação humana.

Recebido em: 23/2/2012 - Aprovado em: 6/6/2012

\section{Referências bibliográficas}

BARBOSA, Rosangela Nair de Carvalho. A economia solidária como política pública: uma tendência de geração de renda e ressignificação do trabalho no Brasil. São Paulo: Cortez, 2007. BEHRING, Elaine Rossetti; BOSCHETTI, Ivanete. Politica social: fundamentos e história. São Paulo: Cortez, 2008.

BRASIL. Ministério do Trabalho e Emprego. Programa Nacional de Estímulo ao Primeiro Emprego. Brasília, 2008. Disponível em: <http:www.mte.gov.br/políticas_juventude/acoespnpe_conssociajuvent>. Acesso em: 10 maio 2008.

BRASIL. Ministério do Trabalho e Emprego. Programa Nacional de Microcrédito Produtivo Orientado. Brasília, 2009. Disponível em: <http://www.mte.org.br/pnmpo >. Acesso em: 10 ago. 2011.

. Ministério do Trabalho e Emprego. Programa Nacional de Estímulo ao Primeiro Emprego. Brasília, 2011. Disponível em: $<$ http:www.mte.gov.br/políticas_juventude/acoespnpe_conssociajuvent>. Acesso em: 10 ago. 2011.

. Ministério do Trabalho e Emprego. Programa de Aprendizagem Profissional. Brasília, 2011. Disponível em: <http://www.mte.org.br>. Acesso em: 15 ago. 2009.

. Ministério do Trabalho e Emprego. Programa de Intermediação da Mão de Obra. Brasília, 2011. Disponível em: <http://www.mte.org.br>. Acesso em: 20 ago. 2009. 
BRASIL. Ministério do Trabalho e Emprego. Programa Economia Solidária em Movimento. Brasília, 2011. Disponível em: <http://www.mte.org.br/ecosolidaria> Acesso em: 25 ago. 2011. CARDOSO, J. C. Crise e desregulamentação do trabalho no Brasil. Brasília: Ipea, 2002.

DIEESE. Pesquisa de emprego e desemprego. Disponível em: <http://www.dieese.org.br>. Acesso em: 8 nov. 2011.

FAUSTO, Boris. A revolução de 1930: historiografia e história. São Paulo: Brasiliense, 1995.

IBGE. Indicadores sociais mínimos. Rio de Janeiro: IBGE, 2011.

MARCONSIN, Cleier. Cerco aos direitos trabalhistas e crise do movimento sindical no Brasil contemporâneo. Tese (Doutorado em Serviço Social) - Universidade Federal do Rio de Janeiro, Rio de Janeiro, 2009.

MARX, Karl. O capital: crítica da economia política. Rio de Janeiro: Civilização Brasileira, 1988. Livro I, v. I.

OLIVEIRA, Ednéia Alves. A política pública de emprego: entre a precarização desprotegida e a precarização desprotegida. Um estudo comparativo entre Brasil e Itália. Tese (Doutorado em Serviço Social) - Universidade Federal do Rio de Janeiro, Rio de Janeiro, 2010.

POCHMANN, Márcio. Rumos da política do trabalho no Brasil. In: SILVA, M. O. S.; YASBECK, C. Políticas públicas de trabalho e renda no Brasil contemporâneo. São Paulo: Cortez; São Luís, MA: Fapema, 2008. 